Objectives: In patients with active r-axSpA, to assess the analgesic efficacy of IXE as it relates to patient-reported and objective measures of inflammation. Methods: The Phase III COAST-V (NCT02696785) multi-center, randomized, double-blind, placebo (PBO)-controlled and active reference arm with adalimumab (ADA) trial investigated the efficacy of IXE in 341 patients (pts) with active r-axSpA for 52 weeks $(W)$. Pts were initially randomized to IXEQ4W, IXEQ2W, PBO, and ADAQ2W. At W16, pts assigned to PBO and ADA were re-randomized to IXEQ2W or Q4W Changes in spinal pain at night (SP-N) and spinal pain were measured at each study visit and analysed while controlling for CRP levels or mean of BASDAI questions 5 \& 6 (Q5: Duration and Q6: Intensity of morning stiffness). Observed data analyses are presented for each group stratified by treatment arm and compared to PBO. In the initial analysis, pts were categorized into 2 sub-groups defined as "Sustained" and "Fluctuating" depending on: CRP $<5 \mathrm{mg} / \mathrm{L} \mathrm{W} 4-16$ vs. CRP $\geq 5 \mathrm{mg} / \mathrm{L}$ at any point beyond W4 between weeks 4-16 respectively. In a second analysis, pts were categorized based on BASDAI Q5/6 improvement: "Sustained" if $\geq 2$-pt improvement W12-16 vs. "Fluctuating" if <2-pt improvement at any point beyond W12 between W12-16.

Results: Between W0 and W16, pts treated (tx) with IXEQ4W experienced greater reduction in SP-N than pts tx with ADA, in both CRP sustained and fluctuating groups (Fig 1a). Pts in the IXEQ4W and ADA arms showed different trajectories of pain improvement in the CRP fluctuating groups. For the pts with a fluctuating $C R P \geq 5 \mathrm{mg} / \mathrm{L}$, pts in IXEQ4W arm demonstrated a greater reduction in SP-N compared to pts in PBO arm $(p<.001)$ at W16, whereas pts in ADA arm did not experience a reduction in SP-N compared to PBO $(p=.416)$. For the pts with a sustained CRP $<5 \mathrm{mg} / \mathrm{L}$, IXEQ4W and ADA treatments both significantly demonstrated reduction in SP-N compared to PBO at W16 (IXEQ4W: $p=.002$; ADA: $p=.02$ ), with IXEQ4W treatment showing a greater level of reduction (Fig 1a). The pts randomized to ADA and re-randomized to IXEQ2W or Q4W (ADA/IXE) experienced further improvement in SP-N. This effect was sustained over the 52 -wk period (Fig 1b). The same pattern of improvement in SP-N was observed when controlling for the BASDAI Q5/6; the SP-N improvement was greater in pts with a sustained BASDAI Q5/6 compared to pts with a fluctuating BASDAI Q5/6, regardless of treatment (Table 1). In the fluctuating BASDAI Q5/6, for pts in ADA/ IXE arm, further reduction of both spinal pain and SP-N were observed (Table 1).

Figure 1: Change in Spinal Pain at Night (SP-N) over 52 weeks by CRP, in active treatment arms, showing IXE and ADA re-randomized to IXE (Q2W and Q4W combined: ADA/IXE)

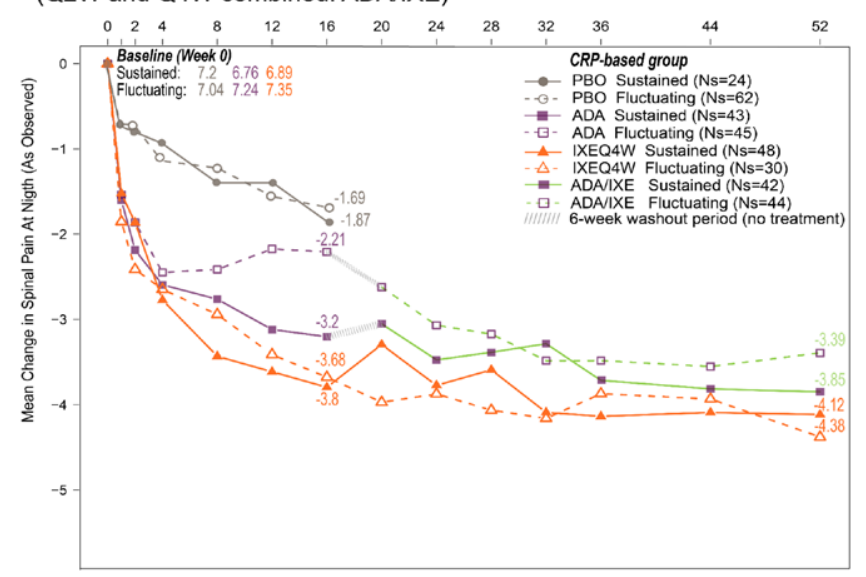

Conclusion: IXE reduced SP-N and spinal pain irrespective of CRP or morning stiffness. Additionally, pts treated with ADA re-randomized to IXE experienced a further reduction in SP-N and spinal pain. Collectively, these results support the additive benefits of IXE in reducing pain above measurable effects on inflammation.

Acknowledgements: The authors would like to thank Eglantine Julle-Daniere for writing and editorial contributions

Disclosure of Interests: Kurt de Vlam Speakers bureau: Eli Lilly, Novartis, Pfizer, Paid instructor for: Celgene, Amgen, Consultant of: Elil Lillyn Novartis, UCB, Galapagos, Sandoz, Pfizer, Grant/research support from: Celgene, Gaia Gallo Shareholder of: Eli Lilly, Employee of: Eli Lilly, Philip J Mease Speakers bureau: AbbVie, Amgen, Eli Lilly, Janssen, Novartis, Pfizer, UCB, Consultant of: AbbVie, Amgen, Boehringer Ingelheim, Bristol Myers Squibb, Eli Lilly, Galapagos, Gilead, GlaxoSmithKline, Janssen, Novartis, Pfizer, Sun, UCB, Grant/research support from: AbbVie, Amgen, Bristol Myers Squibb, Eli Lilly, Galapagos, Janssen, Novartis, Pfizer, Sun, UCB, Proton Rahman Speakers bureau: AbbVie, Amgen, BMS, Celgene, Eli Lilly, Janssen, Merck Novartis, Pfizer, UCB, Consultant of: AbbVie, Amgen, BMS, Celgene, Eli Lilly, Janssen, Merck, Novartis, Pfizer, UCB, Grant/research support from: Janssen, Novartis Venkatesh Krishnan Shareholder of: Eli Lilly, Employee of: Eli Lilly, David Sandoval Shareholder of: Eli Lilly, Employee of: Eli Lilly, Chen-Yen Lin Shareholder of: Eli Lilly, Employee of: Eli Lilly, Rebecca Bolce Shareholder of: Eli Lilly, Employee of: Eli Lilly, Philip G Conaghan Consultant of: personal fees from: AbbVie, AstraZeneca, BMS Eli Lilly, EMD Serono, Flexion Therapeutics, Galapagos, Gilead, Novartis, Pfizer DOI: 10.1136/annrheumdis-2021-eular.211

\section{POS0902 EFFICACY AND SAFETY OF INTRAVENOUS GOLIMUMAB IN ANKYLOSING SPONDYLITIS PATIENTS WITH EARLY VS LATE DISEASE THROUGH WEEK 52 OF GO-ALIVE STUDY}

A. Deodhar ${ }^{1}$, S. Kafka ${ }^{2}$, E. C. Hsia ${ }^{3,4}$, K. H. Lo ${ }^{5}$, L. Kim ${ }^{5}$, S. Xu' , J. D. Reveille ${ }^{6}$ ${ }^{1}$ Oregon Health \& Science University, Division of Arthritis and Rheumatic Diseases, Portland, United States of America; ${ }^{2}$ Janssen Scientific Affairs, LLC, Immunology, Horsham, United States of America; ' Janssen Research \& Development, LLC, Immunology, Spring House, United States of America; ${ }^{4}$ University of Pennsylvania, Rheumatology, Philadelphia, United States of America; ${ }^{5}$ Janssen Research \& Development, LLC, Biostatistics, Spring House, United States of America; ${ }^{6}$ University of Texas McGovern Medical School, Rheumatology And Clinical Immunogenetics, Houston, United States of America

Background: The GO-ALIVE study assessed efficacy and safety of intravenous golimumab (IV GLM) in patients (pts) with ankylosing spondylitis (AS). ${ }^{1,2}$

Objectives: In this post hoc analysis, we assessed IV GLM efficacy and safety in AS pts with early disease (ED) vs late disease (LD) based on pt-reported duration of inflammatory back pain (IBP).

Methods: In this Phase 3, double-blind, placebo (PBO)-controlled trial, pts with active AS were randomized (1:1) to receive IV GLM $2 \mathrm{mg} / \mathrm{kg}$ at Week (W) $0, \mathrm{~W} 4$ then Q8W or PBO at W0, W4, and W12 with crossover to IV GLM at W16, W20, then Q8W through 52. The primary endpoint was achievement of SpondyloArthritis International Society $20 \%$ improvement response (ASAS 20) at W16. In this post hoc analysis, 208 pts were grouped into quartiles based on self-reported duration of IBP symptoms. Efficacy and safety in 60 pts with ED ( $1^{\text {st }}$ quartile) were compared with 52 pts with LD ( $4^{\text {th }}$ quartile).

Results: For the overall study population, mean duration of IBP symptoms was $10.9 \mathrm{yr}$ and mean time since diagnosis was $5.5 \mathrm{yr}$. For ED pts, the mean duration of IBP symptoms ranged from $2.3 \mathrm{yr}$ (IV GLM) to $2.6 \mathrm{yr}$ (PBO), and for LD pts ranged from $23.5 \mathrm{yr}$ (IV GLM) to $24.4 \mathrm{yr}$ (PBO). At W16, ASAS 20 was achieved by $72 \%$ IV GLM vs $32 \%$ PBO pts with ED and by $67 \%$ IV GLM vs $21 \%$ PBO pts with LD. Pts with ED had numerically better response than those with LD in Bath Ankylosing Spondylitis Functional Index (BASFI), Bath Ankylosing Spondylitis Metrology Index (BASMI), and across more stringent endpoints, including ASAS 40, Bath Ankylosing Spondylitis Disease Activity Index 50\% improvemen

Table 1. Change in Pain Outcome at baseline, week 16 and week 52 by Inflammation Status as assessed by BASDAl or CRP levels for patients receiving placebo (PBO), adalimumab (ADA), and ixekizumab every 4 weeks (IXE Q4W)

Change from baseline

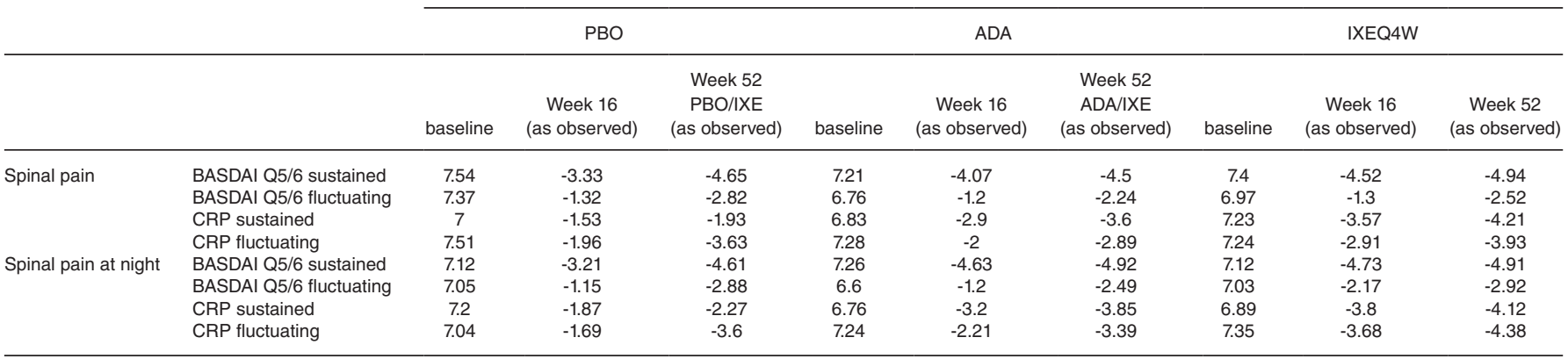


(BASDAI 50), and Ankylosing Spondylitis Disease Activity Score (ASDAS) inactive disease and major improvement (Table 1). Response rates at W16 among IV GLM-treated pts were generally consistent through 1 year in both ED and LD subgroups; also in ED and LD subgroups, pts crossing over to IV GLM at W16 demonstrated response at W52 consistent with pts who started IV GLM at W0. At W16, improvements in enthesitis score were similar for pts with ED (mean change -2.9 for IV GLM vs 0.1 for PBO) and LD (mean change -2.5 for IV GLM vs 0.6 for PBO); improvements were maintained at W52 for ED and LD pts. Treatment-emergent adverse events and serious adverse events through 1 year were $46 \%$ and $3 \%$ for pts with ED compared with $61 \%$ and $2 \%$ for pts with LD, respectively.

Conclusion: While IV GLM provided clinically meaningful improvements in signs and symptoms of AS in pts regardless of disease duration, response generally appeared numerically better in pts with ED than in pts with LD. This supports the principle of prompt diagnosis and early treatment.

REFERENCES:

[1] Deodhar A, et al. J Rheumatol. 2018;45:341-348.

[2] Reveille J, et al. J Rheumatol. 2019;46:1277-1283.

Table 1. Efficacy Outcomes

\begin{tabular}{|c|c|c|c|c|c|c|c|c|}
\hline & \multicolumn{4}{|c|}{ ED } & \multicolumn{4}{|c|}{ LD } \\
\hline & \multicolumn{2}{|c|}{ Week 16} & \multicolumn{2}{|c|}{ Week 52} & \multicolumn{2}{|c|}{ Week 16} & \multicolumn{2}{|c|}{ Week 52} \\
\hline & $\begin{array}{l}\text { PBO } \\
(n=25)\end{array}$ & $\underset{\substack{\text { IV } \\
(n=35)}}{\substack{\text { GLM } \\
\text { (n) }}}$ & $\begin{array}{c}\text { PBO } \rightarrow \text { IV } \\
\text { GLM } \\
(n=25)\end{array}$ & $\underset{\substack{\text { IV } \\
(n=35)}}{\substack{\text { GLM } \\
\text { (n) }}}$ & $\begin{array}{l}\text { PBO } \\
(n=28)\end{array}$ & 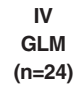 & $\begin{array}{c}\mathrm{PBO} \rightarrow \mathrm{IV} \\
\mathrm{GLM} \\
(\mathrm{n}=28)\end{array}$ & $\begin{array}{c}\text { IV } \\
\text { GLM } \\
(n=24)\end{array}$ \\
\hline ASAS 20 & $32 \%$ & $71 \%$ & $68 \%$ & $71 \%$ & $21 \%$ & $67 \%$ & $68 \%$ & $63 \%$ \\
\hline ASAS 40 & $12 \%$ & $46 \%$ & $56 \%$ & $60 \%$ & $4 \%$ & $42 \%$ & $57 \%$ & $42 \%$ \\
\hline BASDAI 50 & $12 \%$ & $40 \%$ & $64 \%$ & $60 \%$ & $7 \%$ & $33 \%$ & $57 \%$ & $42 \%$ \\
\hline $\begin{array}{l}\text { ASDAS inactive } \\
\text { disease (score } \\
<1.3 \text { ) }\end{array}$ & $4 \%$ & $17 \%$ & $44 \%$ & $37 \%$ & $0 \%$ & $8 \%$ & $14 \%$ & $4 \%$ \\
\hline $\begin{array}{l}\text { ASDAS major } \\
\text { improvement }\end{array}$ & $n=24$ & $57 \%$ & $n=24$ & $51 \%$ & $0 \%$ & $n=23$ & $46 \%$ & $n=23$ \\
\hline (decrease $\geq 2.0$ ) & $4 \%$ & & $54 \%$ & & & $48 \%$ & & $30 \%$ \\
\hline $\begin{array}{l}\text { ASDAS clinically } \\
\text { important }\end{array}$ & $n=24$ & $77 \%$ & $n=24$ & $77 \%$ & $18 \%$ & $\mathrm{n}=23$ & $61 \%$ & $n=23$ \\
\hline $\begin{array}{l}\text { improvement } \\
\text { (decrease } \geq 1.1 \text { ) }\end{array}$ & $29 \%$ & & $75 \%$ & & & $91 \%$ & & $65 \%$ \\
\hline Mean change from & $n=23$ & -2.3 & $n=23$ & -2.8 & $n=27$ & $n=24$ & $\mathrm{n}=27$ & $n=23$ \\
\hline $\begin{array}{l}\text { baseline (SD) in } \\
\text { BASFI }\end{array}$ & $\begin{array}{l}-0.4 \\
(2.0)\end{array}$ & (2.1) & $\begin{array}{l}-2.7 \\
(2.7)\end{array}$ & (2.6) & $\begin{array}{l}-0.3 \\
(1.8)\end{array}$ & $\begin{array}{l}-2.2 \\
(1.7)\end{array}$ & $\begin{array}{l}-2.4 \\
(2.2)\end{array}$ & $\begin{array}{l}-2.3 \\
(1.7)\end{array}$ \\
\hline Mean change from & $n=23$ & -0.4 & $\mathrm{n}=23$ & -0.3 & $\mathrm{n}=27$ & $\mathrm{n}=21$ & $\mathrm{n}=27$ & $n=20$ \\
\hline $\begin{array}{l}\text { baseline (SD) in } \\
\text { BASMI }\end{array}$ & $\begin{array}{l}-0.3 \\
(0.7)\end{array}$ & $(0.7)$ & $\begin{array}{l}-0.6 \\
(0.7)\end{array}$ & $(0.5)$ & $\begin{array}{l}0.01 \\
(0.5)\end{array}$ & $\begin{array}{l}-0.3 \\
(0.6)\end{array}$ & $\begin{array}{l}-0.4 \\
(0.7)\end{array}$ & $\begin{array}{l}-0.3 \\
(0.7)\end{array}$ \\
\hline Mean change from & $n=23$ & -2.9 & $n=23$ & -3.2 & $\mathrm{n}=27$ & $\mathrm{n}=21$ & $\mathrm{n}=27$ & $n=20$ \\
\hline $\begin{array}{l}\text { baseline (SD) in } \\
\text { enthesitis score }\end{array}$ & $\begin{array}{c}0.1 \\
(3.6)\end{array}$ & (2.9) & $\begin{array}{l}-2.0 \\
(4.4)\end{array}$ & (2.5) & $\begin{array}{l}-0.6 \\
(3.4)\end{array}$ & $\begin{array}{l}-2.5 \\
(3.0)\end{array}$ & $\begin{array}{l}-2.5 \\
(3.1)\end{array}$ & $\begin{array}{l}-3.5 \\
(5.9)\end{array}$ \\
\hline
\end{tabular}

$\mathrm{SD}=$ standard deviation

Disclosure of Interests: Atul Deodhar Speakers bureau: AbbVie, Eli Lilly, Janssen, Novartis, Pfizer, UCB, Consultant of: AbbVie, Amgen, Boehringer Ingelheim, Bristol Myers Squibb, Celgene, Eli Lilly, Galapagos, GlaxoSmithKline, Janssen, Novartis, Pfizer, and UCB, Grant/research support from: AbbVie, Eli Lilly, GlaxoSmithKline, Novartis, Pfizer, and UCB, Shelly Kafka Shareholder of: Johnson \& Johnson, Employee of: Janssen Research \& Development, LLC, Elizabeth C Hsia Shareholder of: Johnson \& Johnson, Employee of: Janssen Research \& Development, LLC, Kim Hung Lo Shareholder of: Johnson \& Johnson, Employee of: Janssen Research \& Development, LLC, Lilianne Kim Shareholder of: Johnson \& Johnson, Employee of: Janssen Research \& Development, LLC, Stephen Xu Shareholder of: Johnson \& Johnson, Employee of: Janssen Research \& Development, LLC, John D Reveille Consultant of: Eli Lilly and UCB, Grant/research support from: Eli Lilly and Janssen

DOI: 10.1136/annrheumdis-2021-eular.220

\section{POS0903 CLINICAL AND RADIOLOGICAL MANIFESTATIONS OF COXITIS IN PATIENTS WITH ANKYLOSING SPONDYLITIS (AS) TREATED WITH TNF-ALPHA INHIBITOR GOLIMUMAB: RESULTS OF A 24-MONTHS OBSERVATION (GO-COX STUDY)}

S. Erdes ${ }^{1}$, E. Agafonova ${ }^{1}$, D. Rumiantceva ${ }^{1}$, S. Davidian ${ }^{2}$, E. Zemerova ${ }^{3}$, A. Kulikov ${ }^{4}$, O. Markova ${ }^{5}$, E. Lukyanova ${ }^{6}$, V. Achikyan ${ }^{6} .{ }^{1}$ Federal Rheumatology Research Institute n.a. V.A.Nasonova, Laboratory of Spondyloarthritis and Psoriatic Arthritis, Moscow, Russian Federation; ${ }^{2}$ National Medical and Surgical Center named after N.I. Pirogov, Rheumatology, Moscow, Russian Federation; ${ }^{3}$ Khanty-Mansiysk Autonomous Region - Yugra Regional Clinical Hospital, Rheumatology, Khanty-Mansiysk, Russian Federation; ${ }^{4}$ Rostov-on-Don
Regional Clinical Hospital \#2, Rheumatology, Rostov-on-Don, Russian Federation; ${ }^{5}$ Yakutsk Clinic Lotos, Rheumatology, Yakutsk, Russian Federation; ${ }^{6}$ MSD Pharmaceuticals LLC, Medical Affairs, Moscow, Russian Federation

Background: Coxitis (hip joint inflammation) in AS is associated with worse BASFI scores due to hip joint involvement and more severe axial disease [1] Radiological index of BASRI-hip, US and MRI findings may be used for evaluation of hip joint impairment [2,3,4]. Number of studies on coxitis in AS patients treated with biologics was limited at time of this study initiation.

Objectives: To evaluate clinical changes measured by BASFI, BASMI, BASDAI, ASDAS-CRP and radiological changes in AS patients with coxitis (BASRI-hip hip MRI [STIR- and T1-weighted sequences], hip US) after 12 and 24 months of treatment with TNF alpha inhibitor golimumab from baseline.

Methods: A non-interventional prospective cohort study. Bio-naïve patients with AS and coxitis were treated with golimumab according to daily clinical practice in 5 clinics across Russia and followed up for 24 months. 39 patients participated. This analysis includes data from 30 patients who completed the follow up. The whole cohort's data to be presented after consolidation of safety data. MRI and US data were collected for 12 months in up to 28 of 30 patients. The primary endpoint was mean change of BASFI which was expected to be $-2.5( \pm 2.12)$ from baseline at week 52 weeks (12 months) of therapy [5]. The power of the study was $90 \%$ with minimum sample size of 18 patients. Student's paired t-criteria, Wilcoxon signed rank test were used to compare quantitave and Chi-square test for qualitative variables.

Results: Majority of participants $(66,7 \% ; 20$ out of 30$)$ were male, with mean (SD) age of 33.2 (9.4) years, mean (SD) duration of AS was 36.2 (42.1) months, mean (SD) duration of coxitis was 36.9 (44.1) months. Baseline mean (SD) scores were: BASFI 3.9 (2.5), BASMI 3.1 (2.5), BASDAI 4.9 (2.0), ASDAS-CRP 3.5 (1.2). Changes of mean clinical scores from baseline after 12 and 24 months of treatment with golimumab were: $\triangle B A S F I=-2.2(p=0.0001),-2.1 \quad(p=0.0000)$; $\triangle \mathrm{BASMl}=-1.5(\mathrm{p}=0.0000),-1,8 \quad(\mathrm{p}=0.0000) ; \Delta \mathrm{BASDAl}=-3.0(\mathrm{p}=0.0000),-3.1$ $(p=0.0000) ; \triangle A S D A S-C R P=-2.0 \quad(p=0.0000),-2.1 \quad(p=0.0000)$, correspondingly $(n=30)$. The clinical results (medians, interquartile ranges, min and max) are presented below.

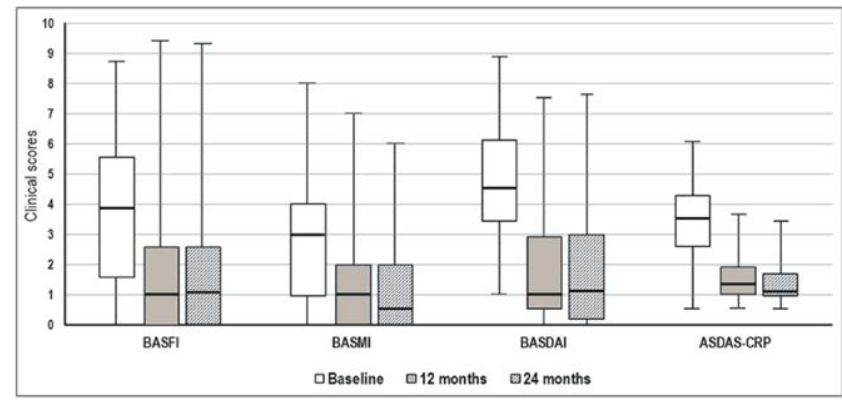

Baseline mean (SD)/median BASRI-hip was $1.1(0.8) / 1.0$ on the right and on the left. Changes of mean/median BASRI-hip score at 12 and 24 months compared to baseline were: $0.3 / 0.0(n=25 ; p=0.2344)$ and $0.3 / 0.0(n=25 ; p=0.1368)$ on the right; $0.4 / 0.0(n=25 ; p=0.0352)$ and $0.4 / 1.0(n=25 ; p=0.0735)$ on the left. Rates of patients with $\mathrm{MRI}$ and US findings are presented below.

\begin{tabular}{lcccc}
\hline Hip MRI, paired analysis & \multicolumn{2}{c}{ Patients (\%), $\mathrm{n}=27$} & \multicolumn{2}{c}{ Patients (\%), $\mathrm{n}=23$} \\
\cline { 2 - 5 } & Baseline & At 6 months & Baseline & At 12 months \\
\hline Right No findings & 33.3 & 48.1 & 39.1 & 56.5 \\
Subchondral bone marrow & 37.0 & 11.1 & 34.8 & 8.7 \\
$\quad$ edema (SBME) & & & & \\
Joint effusion & 74.1 & $25.9^{*}$ & 73.9 & $17.4^{*}$ \\
Enthesitis & 33.3 & 11.1 & 34.8 & 21.7 \\
Fatty degeneration & 37.0 & 55.6 & 34.8 & 52.2 \\
Left & 29.6 & 51.9 & 30.4 & 52.2 \\
No findings & 18.5 & 3.7 & 8.7 & 4.3 \\
SBME & 63.0 & $22.2^{*}$ & 60.9 & 21.7 \\
Joint effusion & 22.2 & 18.5 & 17.4 & 21.7 \\
Enthesitis & 33.3 & 55.6 & 30.4 & 52.2 \\
Fatty degeneration & Patients $(\%), \mathrm{n}=28$ & Patients (\%), $\mathrm{n}=27$ \\
US, paired analysis & Baseline & At 6 months & Baseline & At 12 months \\
Hip & 14.3 & $50.0^{*}$ & 18.5 & $51.9^{*}$ \\
Right No findings & 46.4 & 25.0 & 51.9 & $11.1^{*}$ \\
Joint effusion & 25.0 & 14.3 & 18.5 & 14.8 \\
Enthesitis & 14.3 & $50.0^{*}$ & 18.5 & $55.6^{*}$ \\
Left & 42.9 & 28.6 & 48.1 & 25.9 \\
No findings & 17.9 & 17.9 & 11.1 & 18.5 \\
Joint effusion & & & & \\
Enthesitis & & & & \\
\hline
\end{tabular}

${ }^{*} p<0.05$ 